\title{
Kinetics of the Autoreduction of Hexavalent Americium in Aqueous Nitric Acid
}

Travis S. Grimes, Gregory P. Horne, Christopher J. Dares, Simon M. Pimblott, Stephen P. Mezyk, Bruce J. Mincher June 2017

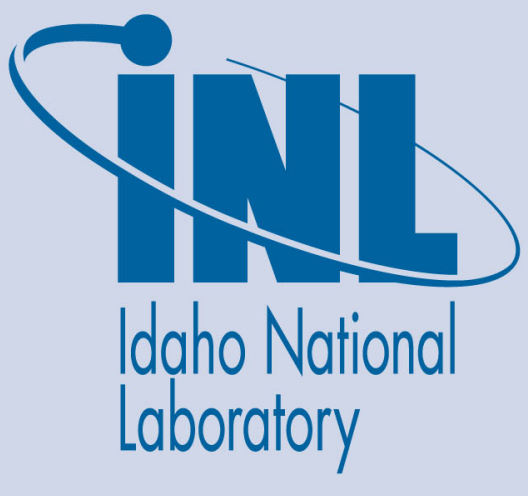

The INL is a U.S. Department of Energy National Laboratory operated by Battelle Energy Alliance 


\section{Kinetics of the Autoreduction of Hexavalent Americium in Aqueous Nitric Acid}

Travis S. Grimes, Gregory P. Horne, Christopher J. Dares, Simon M. Pimblott, Stephen P. Mezyk, Bruce J. Mincher

June 2017

Idaho National Laboratory Idaho Falls, Idaho 83415

http://www.inl.gov

Prepared for the

U.S. Department of Energy

Under DOE Idaho Operations Office

Contract DE-AC07-05ID14517 


\section{Kinetics of the Autoreduction of Hexavalent Americium in Aqueous Nitric Acid}

Travis S. Grimes, ${ }^{*, 1}$ Gregory P. Horne ${ }^{2,3}$, Christopher J. Dares ${ }^{4}$, Simon M. Pimblott ${ }^{5,6}$, Stephen P. Mezyk ${ }^{2}$, and Bruce J. Mincher ${ }^{1}$

${ }^{1}$ Idaho National Laboratory, Idaho Falls, ID, P.O. Box 1625, 83415, United States

${ }^{2}$ California State University at Long Beach, Long Beach, CA 90804, United States

${ }^{3}$ Radiation Research Laboratory, University of Notre Dame, Notre Dame, IN 46556, United States

${ }^{4}$ Florida International University, Miami, FL 33199, United States

${ }^{5}$ The University of Manchester, Dalton Cumbrian Facility, Westlakes Science and Technology Park, Cumbria, CA24 3HA, United Kingdom

${ }^{6}$ The University of Manchester, School of Chemistry, Oxford Road, Manchester M13 9PL, United Kingdom

\section{ABSTRACT}

The rate of reduction of hexavalent ${ }^{243} \mathrm{Am}$ due to self-radiolysis was measured across a range of total americium and nitric acid concentrations. These so-called autoreduction rates exhibited zero order kinetics with respect to the concentration of hexavalent americium, and pseudo-first order kinetics with respect to the concentration of total americium. However, the rate constants did vary with nitric acid concentration, resulting in values of $0.0048 \pm 0.0003,0.0075 \pm 0.0005$, and 0.0054 $\pm 0.0003 \mathrm{~h}^{-1}$ for $1.0,3.0$, and $6.5 \mathrm{M} \mathrm{HNO}_{3}$, respectively. This indicates that reduction is due to reaction of hexavalent americium with the radiolysis products of total americium decay. The concentration changes of Am(III), Am(V) and Am(VI) were determined by UV-vis spectroscopy. The Am(III) molar extinction coefficients are known; however, the unknown values for the $\mathrm{Am}(\mathrm{V})$ and $\mathrm{Am}(\mathrm{VI})$ absorbances across the range of nitric acid concentrations studied were determined by sensitivity analysis in which mass balance with the known total americium concentration was obtained. The new extinction coefficients and reduction rate constants have been tabulated here. Multi-scale radiation chemical modelling using a reaction set with both known and optimized rate coefficients was employed to achieve excellent agreement with the experimental results, and indicates radiolytically-produced nitrous acid from nitric acid radiolysis, and hydrogen peroxide from water radiolysis are the important reducing agents. Since these species also react with each other, modeling indicated the highest concentrations of these species available for $\mathrm{Am}(\mathrm{VI})$ reduction occurred at 3.0 $\mathrm{M} \mathrm{HNO}_{3}$. This is in agreement with the empirical finding that the highest rate constant for autoreduction occurred at the intermediate acid concentration. 


\section{INTRODUCTION}

Changes in the electronic structure of metal ions can cause profound changes in their chemical properties. For example, the hydrometallurgical industry exploits these chemical property changes by reducing $\mathrm{Cu}^{2+}, \mathrm{Ni}^{2+}, \mathrm{Zn}^{2+}, \mathrm{Cd}^{2+}$, and $\mathrm{Al}^{3+}$ ions in solution and electrodeposition of the zero valent metals onto insoluble cathodes. ${ }^{1-3}$ In acidic aqueous solutions, the $4 f$ element, lanthanide, metal ions prefer the trivalent oxidation state. Actinide elements exhibit a variety of oxidation state preferences due to the shielding of the outer $5 f$ electrons, resulting in slightly more diffuse valence electron orbitals. This difference is manifest with high oxidation states (IV-VI) being typical for the early actinides. Actinides able to obtain the highest valence states, (i.e., V, or VI ) hydrolyze to form linear dioxo cations in aqueous solution; in this process, the shape of the metal ion changes from a spherical geometry to a linear molecule with two axial oxygen atoms bonded to the metal ion in a trans configuration, in turn altering their charge density. ${ }^{4-6}$ The preferred oxidation state of americium is trivalent in acidic solution. However, the hexavalent state is possible, but is a challenge to reach given the high Am(IV/III) redox couple $(2.62 \mathrm{~V}$ vs. the saturated calomel electrode, SCE), and also a challenge to maintain since it is thermodynamically and radiolytically unstable. ${ }^{7}$ Understanding the mechanisms which result in its redox instability are paramount to the design of new experiments to further explore the properties of this relatively unknown species.

In addition to enriching our knowledge of $5 f$ element chemistry, the hexavalent state of americium may have practical utility toward nuclear fuel recycle separations. Metal ion charge density has always been the basis for separating $\mathrm{U}, \mathrm{Np}$, and $\mathrm{Pu}$ from the fission products since ligand-specific actinide complexation strength follows $\mathrm{An}(\mathrm{IV})>\mathrm{An}(\mathrm{VI}) \geq \mathrm{An}(\mathrm{III})>\mathrm{An}(\mathrm{V}) .{ }^{8}$ For example, oxidation state adjustments are currently used to minimize or maximize the extraction of plutonium in the PUREX (Plutonium Uranium Reduction EXtraction) separations schemes used worldwide. ${ }^{9-12}$ Recent studies have demonstrated $5 f$ element group co-extraction of U(VI), Pu(VI), $\mathrm{Np}(\mathrm{VI})$, and Am(VI) using numerous extractants. ${ }^{13-15}$ These studies demonstrate a simplified pathway to separate americium from the trivalent lanthanides and curium; widely regarded as one of the most challenging separations in radiochemistry.

The first accounts of americium oxidation were reported by Asprey, Stephanou and Penneman in $1951 .^{16,17}$ In these studies Am(III) was completely oxidized to Am(VI) using ammonium peroxydisufate in nitric or perchloric acids. Shortly after, Werner and Perlman isolated Am(V) from carbonate media using the oxidant sodium hypochlorite at high $\mathrm{pH} .{ }^{18}$ These initial reports were qualitative in nature, describing the UV-vis absorbance peaks of the Am(V) and Am(VI) species and the linear reduction of $\mathrm{Am}(\mathrm{VI})$ to $\mathrm{Am}(\mathrm{V})$ over time. These early reports also suggested the $A m(V)$ and $A m(V I)$ species were analogous to other high valent actinide elements (e.g., U, $\mathrm{Np}$, and $\mathrm{Pu}$ ) and present as actinyl ions in solution. A number of studies were conducted in the following decade to characterize the newly discovered higher valent americium species and to isolate the unobserved, but proposed Am(IV) species, eventually yielding what are now accepted as the formal reduction potentials for $\mathrm{Am}^{0} \rightarrow \mathrm{Am}(\mathrm{III}) \rightarrow \mathrm{Am}(\mathrm{IV}) \rightarrow \mathrm{Am}(\mathrm{V}) \rightarrow \mathrm{Am}(\mathrm{VI})$ to be $+2.07 \mathrm{~V},-2.62 \mathrm{~V},-0.84 \mathrm{~V},-1.60 \mathrm{~V}$, respectively in $1.0 \mathrm{M}$ perchloric acid. ${ }^{7}$ The so-called 
autoreduction of $\mathrm{Am}(\mathrm{VI})$ was reported to occur via an autocatalytic mechanism where americium reacts with its own radiolysis products formed by $\alpha$-decay. ${ }^{16,17,19-24}$

The varied experimental procedures and multiple aqueous media investigated previously have resulted in the report of inconsistent reduction mechanisms and rate constants. Given this group's interest in the chemistry of $\mathrm{Am}(\mathrm{VI})$ its autoreduction kinetics have been re-investigated. The oxidation experiments were conducted in aqueous nitric acid using ${ }^{243} \mathrm{Am}$. Nitric acid is itself redox active under radiolysis. Therefore, the measured Am(VI) reduction kinetics were compared to modeled Am(VI) reduction kinetics, using multi-scale modeling techniques that have previously been applied to understanding the radiolytic reduction of $\mathrm{Np}(\mathrm{VI})$ in nitric acid. ${ }^{25,26}$

\section{EXPERIMENTAL}

2.1. Reagents. Weighed amounts of americium oxide $\left(99.9 \%{ }^{243} \mathrm{Am}_{2} \mathrm{O}_{3}, 0.1 \%{ }^{241} \mathrm{Am}_{2} \mathrm{O}_{3}\right)$ from stock on-hand at Idaho National Laboratory were dissolved in $3.5 \mathrm{~mL}$ of $0.5 \mathrm{M} \mathrm{HNO}_{3}$ in a radiological glovebox to produce stock solutions of $\approx 2.85 \mathrm{mg} / \mathrm{mL}$. Aliquots of the stocks were diluted with standardized $\mathrm{HNO}_{3}(\geq 99.999 \%$ trace metal basis, Sigma Aldrich) and $18 \mathrm{M} \Omega$ deionized $\mathrm{H}_{2} \mathrm{O}$ to produce a series of working solutions with concentrations of $1.0,2.0$, or $4.0 \mathrm{mM}$ americium in $1.0,3.0$, or $6.5 \mathrm{M} \mathrm{HNO}_{3}$. The solutions were assayed by alpha spectroscopy and determined to be $0.98 \mathrm{mM} \pm 4.9 \%, 1.95 \mathrm{mM} \pm 2.9 \%$, and $4.01 \mathrm{mM} \pm 3.3 \%$ for the nominal 1.0, 2.0, and $4.0 \mathrm{mM}$ solutions.

2.2. Americium(III) Oxidation Procedure. The oxidant sodium bismuthate $\left(\mathrm{NaBiO}_{3}, 93 \%\right.$ ACS Grade) was purchased from Chemsavers. Oxidation of Am(III) was achieved by combining $1.5 \mathrm{~mL}$ of an $\mathrm{Am}(\mathrm{III})$ stock solution and $60 \mathrm{mg} \mathrm{mL}^{-1}$ of the solid $\mathrm{NaBiO}_{3}$. Americium solutions of 6.5 $\mathrm{M} \mathrm{HNO}_{3}$ required $2 \mathrm{~h}$ of vigorous shaking, americium solutions of $1.0 \mathrm{M}$ and $3.0 \mathrm{M} \mathrm{HNO}_{3}$ required 24 h of vigorous shaking to yield $\approx 80-85 \% \mathrm{Am}(\mathrm{VI})$, with smaller amounts of $\mathrm{Am}(\mathrm{V})$ and residual Am(III). After shaking, the heterogeneous $\mathrm{Am} / \mathrm{NaBiO}_{3}$ mixture was transferred to a 10 $\mathrm{mL}$ syringe with a glass Pasteur pipette and the undissolved $\mathrm{NaBiO}_{3}$ filtered off using a $25 \mathrm{~mm}$ syringe disk filter with a $0.2 \mu \mathrm{m}$ PTFE membrane (PALL Life Sciences, VWR). The solution containing the oxidized americium was collected in a glass $20 \mathrm{~mL}$ scintillation vial. The americium solution was then transferred into a screw cap semi-micro $10 \mathrm{~mm}$ path length quartz cuvette (Starna) for UV-vis analysis.

A single experiment was conducted in $3.0 \mathrm{M} \mathrm{HNO}_{3}$ with $20 \mathrm{mg} \mathrm{mL}^{-1}$ copper(III) periodate $\left(\mathrm{Na}_{5}\left[\mathrm{Cu}\left(\mathrm{IO}_{5}\right)(\mathrm{OH})_{2}\right] \cdot 12 \mathrm{H}_{2} \mathrm{O}\right.$ as the oxidizing agent. Unlike sodium bismuthate, copper (III) periodate is immediately soluble, and the solution was transferred without filtration to a $10 \mathrm{~mm}$ cuvette for UV-vis analysis.

2.3. Data Collection and Interpretation. The americium oxidation states were monitored by UV-vis absorption spectroscopy. Data were collected using an Agilent Cary-6000i UV-vis-NIR spectrophotometer at ambient temperature $\left(20 \pm 1^{\circ} \mathrm{C}\right)$ in a $10 \mathrm{~mm}$ cuvette. A typical scan range was $1050-450 \mathrm{~nm}(0.5 \mathrm{~nm}$ interval, $2.0 \mathrm{SBW})$ to include the 996, 718, and $503 \mathrm{~nm}$ peaks that 
correspond to $\mathrm{Am}(\mathrm{VI}), \mathrm{Am}(\mathrm{V})$, and $\mathrm{Am}(\mathrm{III})$ respectively. Americium absorption data were baseline corrected and converted to concentrations using the known extinction coefficients for $\mathrm{Am}(\mathrm{III})$, and extinction coefficient values determined by sensitivity analysis for $\mathrm{Am}(\mathrm{V})$ and $\mathrm{Am}(\mathrm{VI})$ (see discussion in the text) using the Beer-Lambert law.

2.4. Multi-Scale Modeling. A combination of stochastic ${ }^{27-29}$ and deterministic methods have been used to model the complex behavior of the aforementioned americium-nitric acid systems. This approach has been successfully used to evaluate the gamma radiolysis of aqueous nitrate, ${ }^{30}$ nitric acid, ${ }^{31}$ and neptunium-nitric acid systems. ${ }^{25,26}$ The chemical reaction set used in these calculations incorporated supplementary americium reactions given in Supporting Information, Table 1.

\section{RESULTS AND DISCUSSION}

3.1. UV-vis Absorption Spectroscopy. The UV-vis absorption spectrum of a mixed $\mathrm{Am}(\mathrm{III}), \mathrm{Am}(\mathrm{V})$ and $\mathrm{Am}(\mathrm{VI})$ solution containing $2.0 \mathrm{mM}$ total americium in $3.0 \mathrm{M} \mathrm{HNO}_{3}$ is shown in Figure 1. A series of these spectra were collected over a 24 hour period, and the decrease in $\mathrm{Am}(\mathrm{VI})$ at 666 and $996 \mathrm{~nm}$, the increase in $\mathrm{Am}(\mathrm{V})$ at 513 and $718 \mathrm{~nm}$, and the stable to slightly increasing absorbance of Am(III) at 503 and $810 \mathrm{~nm}$ are shown.

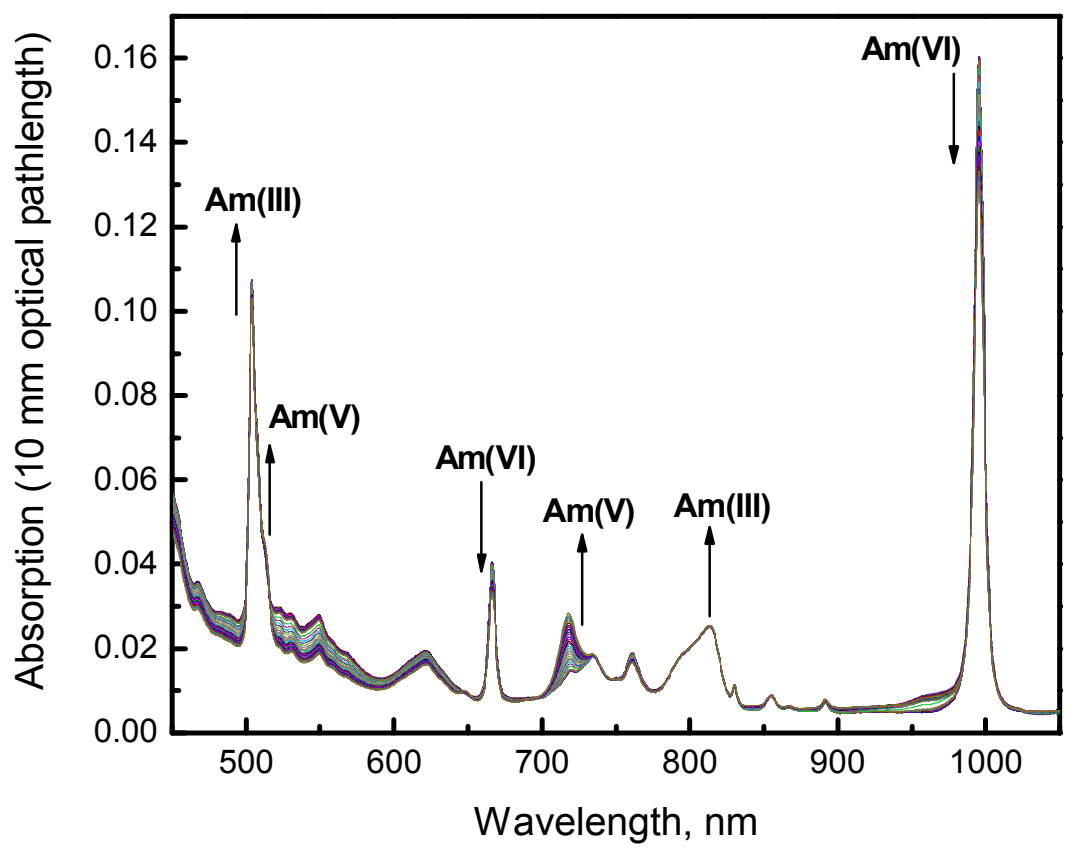

Figure 1. UV-vis absorption spectrum highlighting the multiple Am oxidation state changes as monitored by the indicated wavelengths. The aqueous solution contained $2.0 \mathrm{mM}$ total Am in 3.0 $\mathrm{M} \mathrm{HNO}_{3}$ and was pre-contacted with sodium bismuthate for 24 hours. The arrows indicate the change in absorption peak growth or decay. 
3.2. Respective Molar Extinction Coefficients for the Americium Species. All three americium oxidation states (III, V, and VI) were observed at their absorbance maxima of 503 (Am(III)), $718(\mathrm{Am}(\mathrm{V}))$, and $996 \mathrm{~nm}(\mathrm{Am}(\mathrm{VI}))$. The molar extinction coefficients of penta- and hexavalent americium are not well characterized, especially for the $\mathrm{HNO}_{3}$ concentrations investigated in this work. For Am(III), the extinction coefficient for the $503 \mathrm{~nm}$ peak was extrapolated from the values provided over the range 0.1-5.9 $\mathrm{M} \mathrm{HNO}_{3}$ reported by Zalupski et $a l .{ }^{32}$ Literature values for $\mathrm{Am}(\mathrm{V}), \varepsilon_{718}$, vary from $59.3-66 \mathrm{M}^{-1} \mathrm{~cm}^{-1}$ in dilute $\mathrm{HClO}_{4}$ and/or $\mathrm{H}_{2} \mathrm{SO}_{4} \cdot{ }^{33}$ No extinction coefficients were available in the literature for the $718 \mathrm{~nm}$ absorption peak in $\mathrm{HNO}_{3}$ media. The $\mathrm{Am}(\mathrm{VI}) \varepsilon_{996}$ values vary from $63.8-83.3 \mathrm{M}^{-1} \mathrm{~cm}^{-1}$ in varying concentrations of $\mathrm{HClO}_{4},{ }^{33}$ while the review by Schulz ${ }^{34}$ reports a value of approximately $70 \mathrm{M}^{-1} \mathrm{~cm}^{-1}$ in $3.0-6.0$ $\mathrm{M} \mathrm{HNO}_{3}$. Using initial values within these ranges, the extinction coefficients for $\mathrm{Am}(\mathrm{V})$ and $\mathrm{Am}(\mathrm{VI})$ were varied until an acceptable mass balance for the total americium concentration was obtained for each experiment. The molar extinction coefficients obtained in this work are summarized for all experiments in Table 1.

Table 1. Summary of molar extinction coefficients $(\varepsilon)$ used to calculate the concentrations of each americium oxidation state as a function of nitric acid and total americium concentration.

\begin{tabular}{|c|c|c|c|c|c|}
\hline \multirow[b]{2}{*}[\mathrm{HNO}_{3}]{, $\mathrm{M}$} & \multirow[b]{2}{*}[\mathrm{Am}]{, $\mathrm{mM}$} & \multirow[b]{2}{*}{ Oxidant } & \multicolumn{3}{|c|}{ Molar Extinction Coefficient, $\mathrm{M}^{-1} \mathrm{~cm}^{-1}$} \\
\hline & & & $\varepsilon_{503} \mathrm{Am}(\mathrm{III})$ & $\varepsilon_{718} \mathrm{Am}(\mathrm{V})$ & $\varepsilon_{996} \mathrm{Am}(\mathrm{VI})$ \\
\hline 1.0 & 4.0 & $\mathrm{NaBiO}_{3}$ & 391 & 37.5 & 78.0 \\
\hline 3.0 & 1.0 & $\mathrm{NaBiO}_{3}$ & 356 & 48.8 & 92.6 \\
\hline 3.0 & 2.0 & $\mathrm{NaBiO}_{3}$ & 356 & 43.0 & 95.0 \\
\hline 3.0 & 4.0 & $\mathrm{NaBiO}_{3}$ & 356 & 38.2 & 86.5 \\
\hline 3.0 & 1.0 & $\mathrm{Cu}(\mathrm{III})$ & 356 & 45.0 & 91.0 \\
\hline Average & & & & $43.8 \pm 4.41$ & $91.3 \pm 3.58$ \\
\hline 6.5 & 1.0 & $\mathrm{NaBiO}_{3}$ & 280 & 35.7 & 81.0 \\
\hline 6.5 & 2.0 & $\mathrm{NaBiO}_{3}$ & 280 & 37.5 & 81.0 \\
\hline 6.5 & 4.0 & $\mathrm{NaBiO}_{3}$ & 280 & 37.0 & 80.0 \\
\hline 6.5 & 4.0 & $\mathrm{NaBiO}_{3} /$ dodecane & 280 & 37.0 & 80.0 \\
\hline Average & & & & $36.8 \pm 0.77$ & $80.5 \pm 0.58$ \\
\hline
\end{tabular}


Figure 2 shows the baseline corrected spectra and the corresponding Am(VI) kinetic plots for $2.0 \mathrm{mM}$ total americium in $3.0 \mathrm{M} \mathrm{HNO}_{3}$. For this and all experiments the first one hour of data collection was truncated, because it did not always observe linearity. This was also observed by Hall and Markin ${ }^{23}$ and may indicate trace reducing agents present as impurities. Once these are consumed the reduction of $\mathrm{Am}(\mathrm{VI})$ is attributed to self-radiolysis only. The corresponding americium spectra are shown in panels A, B, and C of Figure 2, which provide the basis for the concentration versus time plot in panel D. The linear plots of panel D shows zero order kinetics, consistent with autoreduction.
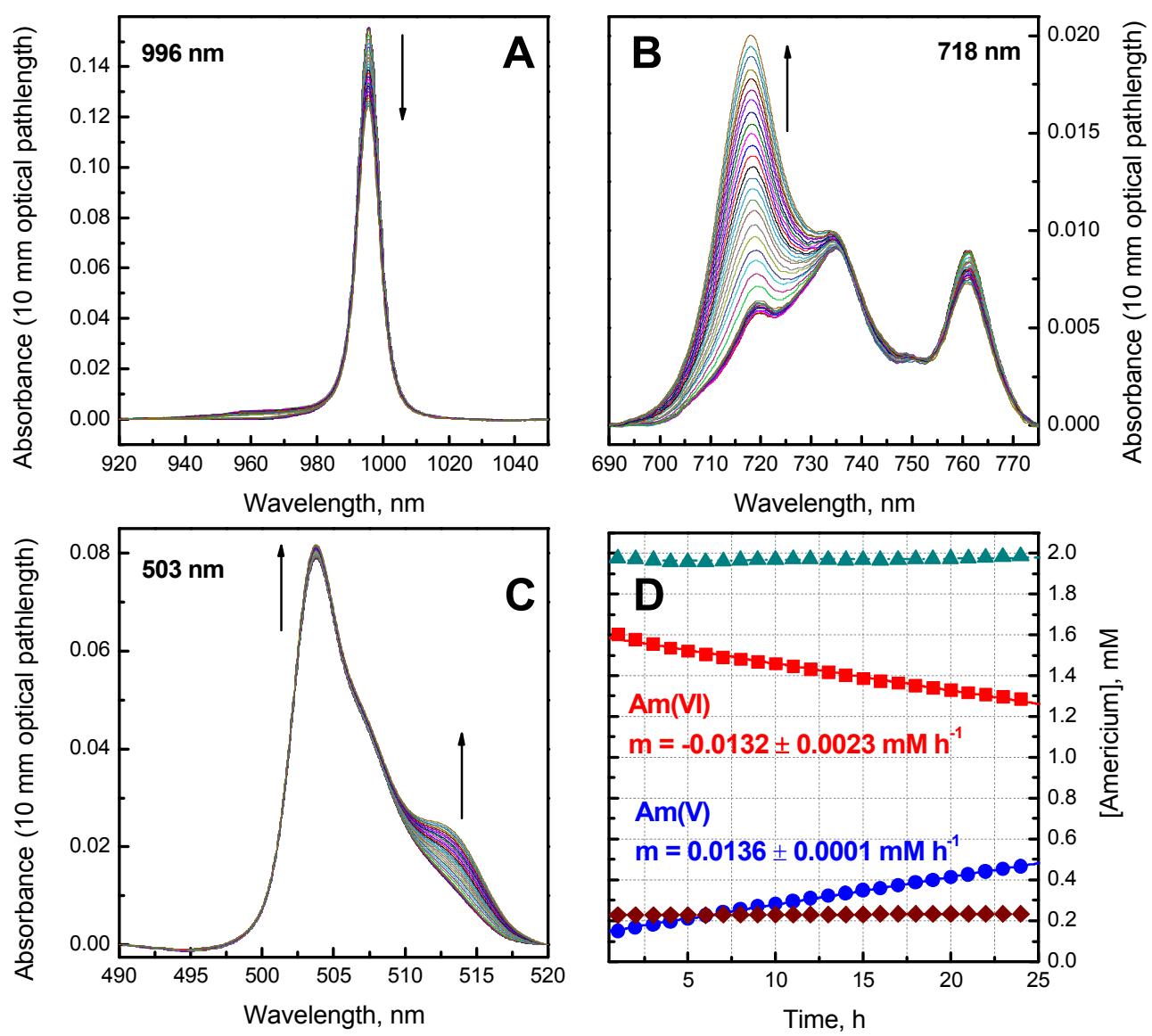

Figure 2. Panels A, B, and C show the base line corrected absorption peaks for $996 \mathrm{~nm}(\mathrm{Am}(\mathrm{VI})), 718 \mathrm{~nm}$ $(\mathrm{Am}(\mathrm{V}))$, and $503 \mathrm{~nm}(\mathrm{Am}(\mathrm{III}))$ used to calculate concentrations of the Am species in solution. Panel D shows the autoreduction of $\mathrm{Am}(\mathrm{VI})(\square)$ in $3.0 \mathrm{M} \mathrm{HNO}_{3}$, for a total Am concentration of nominally $2.0 \mathrm{mM}$, and the simultaneous change in concentration for $A m(V)(\bullet)$ and $A m(I I I)(\diamond)$. Mass balance $(\boldsymbol{\Delta})$ for total americium is $1.970 \pm 0.007 \mathrm{mM}$. The following extinction coefficients were used, $\varepsilon_{503}=356 \mathrm{M}^{-1} \mathrm{~cm}^{-1} ; \varepsilon_{718}$ $=43.0 \mathrm{M}^{-1} \mathrm{~cm}^{-1} ; \varepsilon_{996}=95.0 \mathrm{M}^{-1} \mathrm{~cm}^{-1}$. The best-fit lines in panel $\mathrm{D}$ were obtained using least square linear regression equations. 
The data show both the reduction of $A m(V I)$ and the ingrowth of $A m(V)$ to be linear, with little or no change in Am(III) concentration over the entire 24 hours. The slopes of these curves represent the rates of decrease in $\mathrm{Am}(\mathrm{VI})$ and increase in $\mathrm{Am}(\mathrm{V}) ;-0.0132 \pm 0.0023 \mathrm{mM} \mathrm{h}^{-1}$ and $+0.0136 \pm$ $0.0001 \mathrm{mM} \mathrm{h}^{-1}$, respectively. The mass balance for $[\mathrm{Am}]_{\text {total }}$ of $1.97 \mathrm{mM}$ is in excellent agreement with the $\alpha$-spectroscopy assay result of $1.95 \mathrm{mM} \pm 2 \%$. This total americium concentration value may be used to calculate first order rate constants with respect to the total americium concentration, of $0.0067 \mathrm{~h}^{-1}$ for $\mathrm{Am}(\mathrm{VI})$ and $0.0069 \mathrm{~h}^{-1}$ for $\mathrm{Am}(\mathrm{V})$. Since the zero-order rate constants obtained for $A m(V I)$ reduction are dependent upon the Am concentration, the initial slope values were divided by the total Am concentration (assayed by alpha spectroscopy), to give corresponding firstorder rate constants. This allowed for better comparison of these rate constants under the various conditions of this work, as well as with previous literature ligand degradation values. The Am(III) data may be fitted with a line of positive slope, however; the resulting rate constants are two ordersof-magnitude smaller than those of $\mathrm{Am}(\mathrm{V})$ and $\mathrm{Am}(\mathrm{VI})$. Thus, the agreement between these rates indicates that $\mathrm{Am}(\mathrm{VI})$ undergoes a 1-electron reduction to $\mathrm{Am}(\mathrm{V})$ and the nearly constant $\mathrm{Am}(\mathrm{III})$ concentration indicates that $\mathrm{Am}(\mathrm{V})$ is stable over the 24 hour period of measurement. Any proposed competing reactions, such as a 2-electron reduction of Am(VI) to Am(IV) followed by immediate reduction to $\mathrm{Am}(\mathrm{III})$, or $\mathrm{Am}(\mathrm{V})$ disproportionation, either do not occur or are only marginally significant since the Am(III) concentration remains nearly unchanged.

Analogous data were collected over a range of 1.0-6.5 $\mathrm{M} \mathrm{HNO}_{3}$, with 1.0-4.0 mM total americium concentrations. The resulting rate constants are shown in Table 2. The corresponding plots and the associated rates of $A m(V I)$ reduction and $A m(V)$ growth are given in Supporting Information, Figures 1-6. For each experiment the rates for $A m(V I)$ reduction and $A m(V)$ growth agree as was shown above in Figure 2.

Table 2. Summary of Am(VI) autoreduction and $A m(V)$ growth first-order rate constants.

\begin{tabular}{lllll} 
& & \multicolumn{3}{l}{ Rate Constants, $\mathrm{h}^{-1}$} \\
\cline { 3 - 5 }$\left[\mathrm{HNO}_{3}\right], \mathrm{M}$ & {$[\mathrm{Am}], \mathrm{mM}$} & $\mathrm{Am}(\mathrm{VI})$ & $\mathrm{Am}(\mathrm{V})$ & Average \\
\hline 1.0 & 4.0 & $0.0049 \pm 0.0003$ & $0.0046 \pm 0.0003$ & $0.0048 \pm 0.0003$ \\
\hline 3.0 & 1.0 & $0.0081 \pm 0.0004$ & $0.0079 \pm 0.0004$ & $0.0080 \pm 0.0004$ \\
3.0 & 2.0 & $0.0067 \pm 0.0002$ & $0.0069 \pm 0.0001$ & $0.0068 \pm 0.0003$ \\
3.0 & 4.0 & $0.0075 \pm 0.0004$ & $0.0077 \pm 0.0004$ & $0.0076 \pm 0.0004$ \\
$3.0, \mathrm{Cu}(\mathrm{III})$ & 1.0 & $0.0073 \pm 0.0004$ & $0.0080 \pm 0.0004$ & $0.0077 \pm 0.0004$ \\
Average & & & & $\mathbf{0 . 0 0 7 5} \pm \mathbf{0 . 0 0 0 5}$ \\
\hline 6.5 & 1.0 & $0.0062 \pm 0.0003$ & $0.0050 \pm 0.0003$ & $0.0056 \pm 0.0003$ \\
6.5 & 2.0 & $0.0054 \pm 0.0003$ & $0.0051 \pm 0.0003$ & $0.0053 \pm 0.0003$
\end{tabular}


$\begin{array}{lllll}6.5 & 4.0 & 0.0047 \pm 0.0003 & 0.0045 \pm 0.0003 & 0.0046 \pm 0.0003\end{array}$

$\begin{array}{ll}\text { Average } & \mathbf{0 . 0 0 5 4} \pm \mathbf{0 . 0 0 0 3}\end{array}$

\begin{tabular}{lllll}
\hline 6.5, dodecane & 4.0 & $0.0128 \pm 0.0007$ & $0.0056 \pm 0.0004$ & - \\
\hline
\end{tabular}

The rate of $\mathrm{Am}(\mathrm{VI})$ reduction increases with total americium concentration, as shown for the 3.0 $\mathrm{M} \mathrm{HNO}_{3}$ experiments in Figure 3, (panel A), where the rate of reduction of Am(VI) approximately doubles for each factor of two increase in total americium concentration. This is consistent with the reduction being due to the reaction of hexavalent americium with total americium $\alpha$-radiolysis products. Analogous data were obtained for $6.5 \mathrm{M} \mathrm{HNO}_{3}$, and are shown in Supporting Information, Figure 7. 

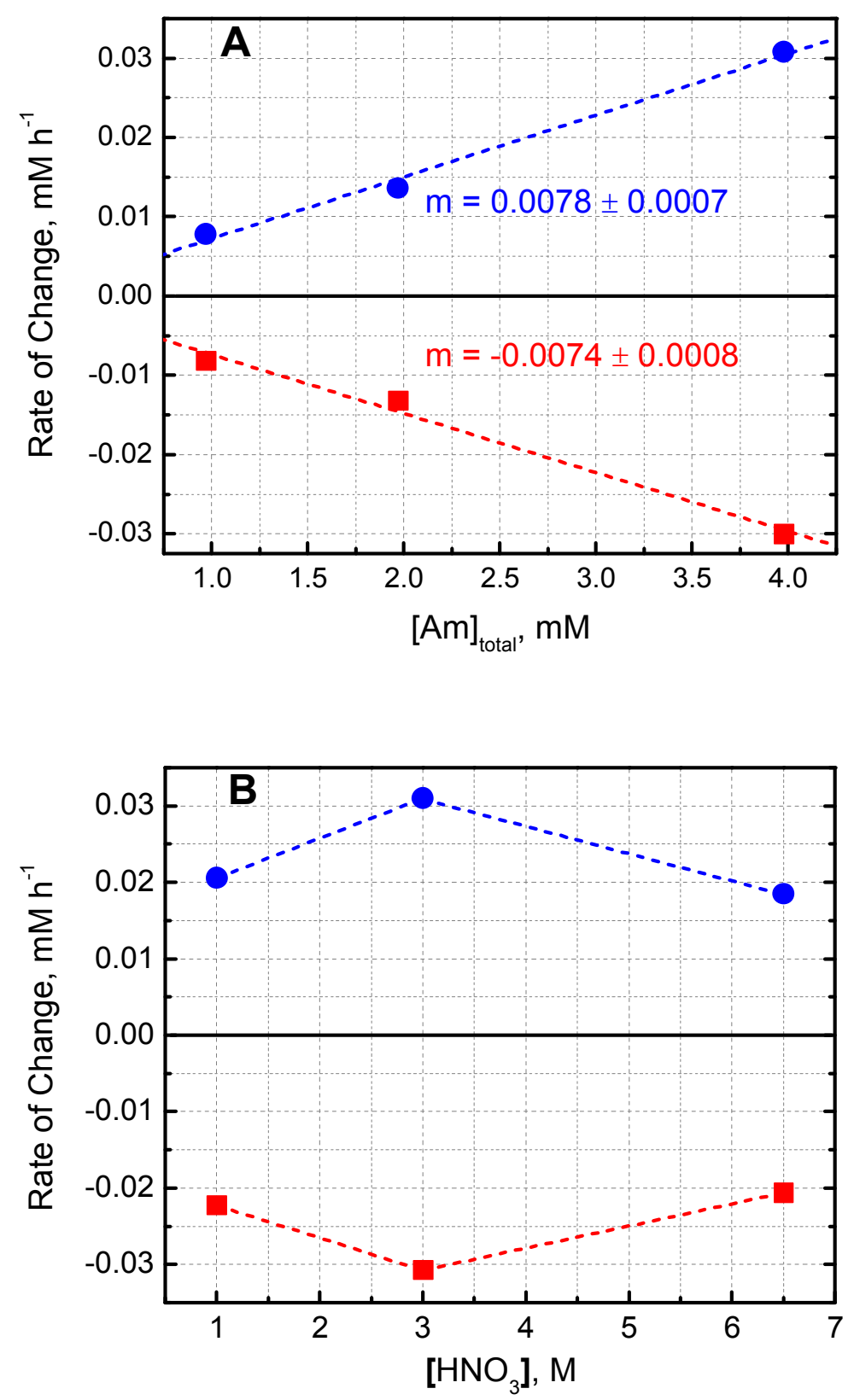

Figure 3. Panel A: Rates of change describing the production of $A m(V)(\bullet)$ and loss of Am(VI) (घ) as a function of total americium concentration in $3.0 \mathrm{M} \mathrm{HNO}_{3}$. The best-fit lines were obtained using least square linear regression equations. Panel B: Rates of change describing Am(V) (•) growth and $\mathrm{Am}(\mathrm{VI})(\square)$ reduction for $4.0 \mathrm{mM}$ americium as a function of nitric acid concentration. The lines in panel B are presented only to guide the eyes and do not represent a best fit. 
The data in (Figure 3, panel B) show the rate of $\mathrm{Am}(\mathrm{VI})$ autoreduction varies with nitric acid concentration for a given total americium concentration. The highest rates are observed in 3.0 $\mathrm{M} \mathrm{HNO}_{3}$, with lower values in $1.0 \mathrm{M}$ and $6.5 \mathrm{M} \mathrm{HNO}_{3}$ (Table 3). These results are not expected since the highest radiolytic production of $\mathrm{HNO}_{2}$ is at the highest nitric acid concentration. ${ }^{25,26}$ This may indicate competition for reaction with $\mathrm{Am}(\mathrm{VI})$ by the products of both water and $\mathrm{HNO}_{3}$ radiolysis, with the intermediate acid concentration being the matrix in which the highest concentrations of both types of reactive species occurs. This is discussed in more detail later.

For comparison, Table 2 also contains kinetic data for the reduction of Am(VI) when oxidized using the alternative oxidant copper(III) periodate (see Supporting Information, Figure 8). ${ }^{35}$ The autoreduction rate constant reported for $\mathrm{Cu}$ (III)-oxidized $\mathrm{Am}(\mathrm{VI})$ is $0.0073 \pm 0.0004 \mathrm{~h}^{-1}$ in 3.0 $\mathrm{M} \mathrm{HNO}_{3}$, and shows no statistical difference (at one sigma error) when compared to the averaged values for $\mathrm{Am}(\mathrm{VI})$ reduction $\left(0.0074 \pm 0.0004 \mathrm{~h}^{-1}\right.$ in $\left.3.0 \mathrm{M} \mathrm{HNO}_{3}\right)$ from bismuthate oxidation (Table 2). This also confirms that any residual bismuthate does not interfere with the autoreduction process being measured, at least after the initial 1 hour when data collection was initiated.

The rate constants given in Table 2 are difficult to compare to previous work given the disparities in the matrix, and the isotope of americium used. For example, Hall and Markin ${ }^{23}$ reported an Am(VI) autoreduction rate constant of $0.031 \pm 0.001 \mathrm{~h}^{-1}$ in $0.2 \mathrm{M} \mathrm{HClO}_{4}$. Those studies were conducted using ${ }^{241} \mathrm{Am}$ with a half-life of $432.7 \mathrm{y}$. The ${ }^{243} \mathrm{Am}$ used in the current work has a half-life of $7.37 \times 10^{3}$ years, but similar $\alpha$-decay energies of $5.4 \mathrm{MeV}$ versus $5.2 \mathrm{MeV}$. Consequently, the yield of radiolysis products capable of reducing Am(VI) is expected to be greater for ${ }^{241} \mathrm{Am}$ by the ratio of these half-lives, which should result in a rate constant 17 times faster for ${ }^{241} \mathrm{Am}$. The rate constant reported by Hall and Markin ${ }^{23}$ is only 6.5 times faster than the slowest rate constant reported here, indicating the irradiated $\mathrm{HClO}_{4}$ medium does not have as high a radiation chemical yield of reducing agents as does $\mathrm{HNO}_{3}$. This strongly suggests $\mathrm{HNO}_{2}$ is indeed an important reducing agent in addition to the $\mathrm{H}_{2} \mathrm{O}_{2}$ produced by the $\alpha$-radiolysis of water. The only data available under comparable conditions to the current work is by Zaitsev, ${ }^{36}$ as reviewed by Schulz ${ }^{34}$ who reported a rate constant $\left({ }^{241} \mathrm{Am}(\mathrm{VI})\right)$ of $0.087 \mathrm{~h}^{-1}$ for 3.0-6.0 $\mathrm{M} \mathrm{HNO}_{3}$; about 12 times faster than the highest value reported here.

In an experiment to simulate solvent extraction conditions similar to the fuel cycle, an equal volume of dodecane was layered over the aqueous phase during the 24 hour UV-vis data collection. Data for the reduction of $\mathrm{Am}(\mathrm{VI})$ in $4.0 \mathrm{mM} / 6.5 \mathrm{M} \mathrm{HNO}_{3}$ in constant contact with dodecane is shown in Figure 4, with the rate constants also summarized in Table 2. The rate constant for the growth of $A m(V)$ was $0.0056 \pm 0.0004 \mathrm{~h}^{-1}$; the same as found for this acid concentration in the absence of dodecane (average $0.0054 \pm 0.0003 \mathrm{~h}^{-1}$ in Table 2), suggesting the rate of Am(VI) autoreduction was unchanged. However, the two-electron reduction is apparently no longer insignificant with a rate constant for Am(III) production of $0.0053 \pm 0.0004 \mathrm{~h}^{-1}$. Trivalent americium is produced by the instantaneous reduction of the $\mathrm{Am}(\mathrm{IV})\left(\left(\mathrm{E}_{\mathrm{red}}=2.6 \mathrm{~V} \text { vs. SCE }\right)^{7}\right.$ produced by the two-electron reduction of hexavalent americium. The combination of these two 
pathways in the presence of the dodecane explain the higher Am(VI) reduction rate constant with its value of $0.0128 \pm 0.0007 \mathrm{~h}^{-1}$.

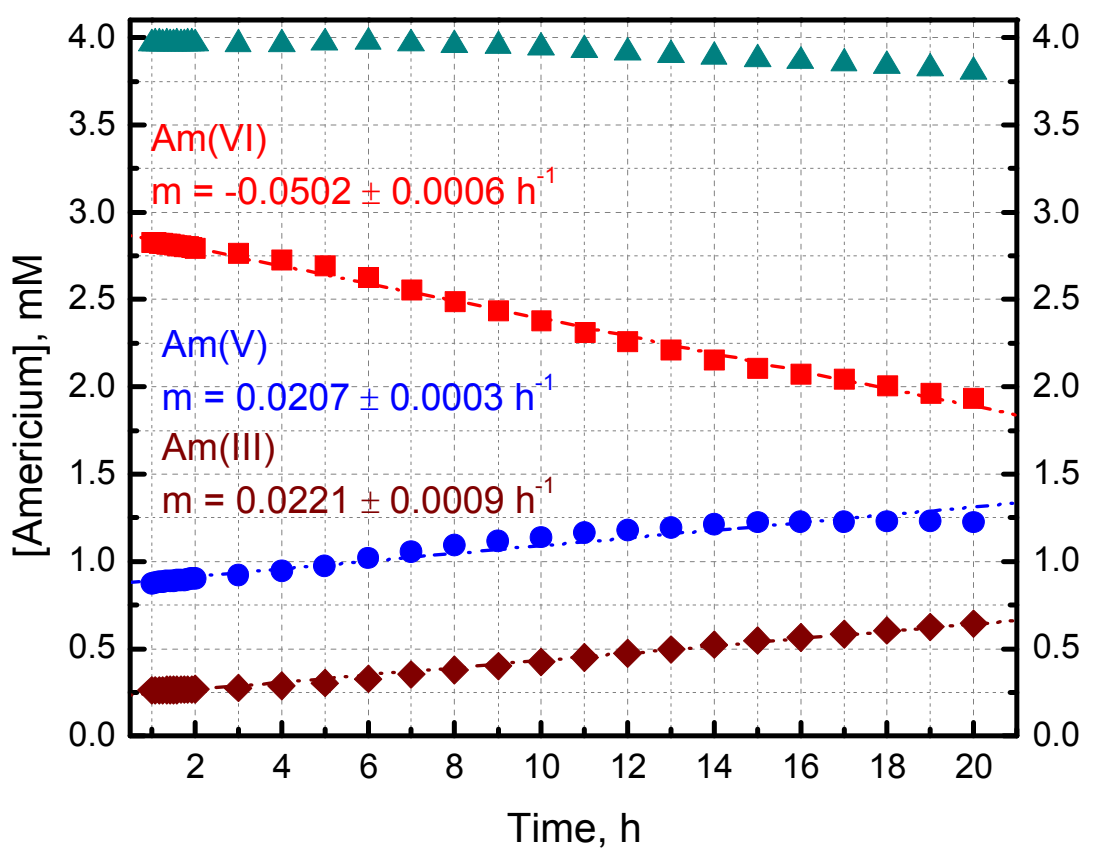

Figure 4. Autoreduction of $\mathrm{Am}(\mathrm{VI})(\square)$ in $6.5 \mathrm{M} \mathrm{HNO}_{3}$ in constant contact with equal volume of dodecane, for a total Am concentration of nominally $4.0 \mathrm{mM}$, and the simultaneous change in concentration for Am(V) $(\odot)$ and Am(III) $(\diamond)$. Mass balance ( $\Delta$ ) for total americium is $3.93 \pm 0.05 \mathrm{mM}$. The following extinction coefficients were used, $\varepsilon_{503}=280 ; \varepsilon_{718}=37.0 ; \varepsilon_{996}=80.0$. The best-fit lines were obtained using least square linear regression equations.

Similar data to those collected here in the presence of dodecane were reported by Dares et $\mathrm{al}^{37}$ for the reduction of $\mathrm{Am}(\mathrm{VI})$ in $0.1 \mathrm{M} \mathrm{HNO}_{3}$ solution where the high valent americium was prepared by electrochemical oxidation using surface functionalized electrodes. These electrodes contained organic complexing agents. The mechanism they proposed also included concurrent one electron and two electron Am(VI) reduction pathways. In that report americium speciation remained static after all $\mathrm{Am}(\mathrm{VI})$ was reduced, indicating that $\mathrm{Am}(\mathrm{V})$ is not as prone to autoreduction, consistent with the fact $\mathrm{Am}(\mathrm{V})$ is a weak oxidant $\left(\mathrm{E}_{\mathrm{red}}=0.84 \mathrm{~V}\right.$ vs. SCE$){ }^{7}$

3.3. Mechanistic Considerations. The main reduction pathway for $A m(V I)$ in aqueous $\mathrm{HNO}_{3}$ might be assumed to be reaction with radiolytically-produced $\mathrm{H}_{2} \mathrm{O}_{2}$ (Equation 1$)^{34}$, due to it being a high-yield product of the $\alpha$-radiolysis of water. ${ }^{38}$

$$
\mathrm{AmO}_{2}{ }^{2+}+\mathrm{H}_{2} \mathrm{O}_{2} \rightarrow \mathrm{AmO}_{2}{ }^{+}+{ }^{\circ} \mathrm{HO}_{2}+\mathrm{H}_{\mathrm{aq}}{ }^{+}
$$


However, the $\alpha$-radiolysis of nitric acid yields comparable amounts of $\mathrm{HNO}_{2}$, which was shown to be an important reducing species in the neptunium-nitric acid system. ${ }^{25,26}$ The significance of $\mathrm{HNO}_{2}$ formation is that it is also a predominant $\mathrm{Am}(\mathrm{VI})$ reducing species and that it reacts with $\mathrm{H}_{2} \mathrm{O}_{2}$ (Equation 3). ${ }^{33}$ Thus the equilibrium between these radiolytically-produced species determines the final concentration of species available to reduce $\mathrm{Am}(\mathrm{VI}){ }^{25}$

$$
\begin{array}{ll}
\mathrm{AmO}_{2}{ }^{2+}+\mathrm{HNO}_{2} \rightarrow \mathrm{AmO}_{2}{ }^{+}+\mathrm{NO}_{2}+\mathrm{H}_{\mathrm{aq}}{ }^{+} & \\
\mathrm{HNO}_{2}+\mathrm{H}_{2} \mathrm{O}_{2} \rightleftharpoons \mathrm{ONOOH}+\mathrm{H}_{2} \mathrm{O} & k_{3 f}=7.17 \times 10^{5} \mathrm{M} \mathrm{s}^{-1} \\
& k_{3 b}=300 \mathrm{M} \mathrm{s}^{-1}
\end{array}
$$

The data show the rate constants for $\mathrm{Am}(\mathrm{VI})$ autoreduction vary as a function of $\mathrm{HNO}_{3}$ concentration (Figure 3 and SI Figure 7). The highest rate constant is found in $3.0 \mathrm{M} \mathrm{HNO}_{3}$, with lower values in 1.0 and $6.5 \mathrm{M} \mathrm{HNO}_{3}$. To begin to understand the observed kinetic trend with solution acidity the changes in both radiation track chemistry and bulk homogeneous chemistry must be fully considered.

3.4. Radiation Track Chemistry. As the concentration of $\mathrm{HNO}_{3}\left(\mathrm{HNO}_{3} \rightleftharpoons \mathrm{NO}_{3}{ }^{-}+\mathrm{H}_{\mathrm{aq}}{ }^{+}, \mathrm{pK}_{\mathrm{a}}\right.$ $\approx-1.37)^{39}$ increases, the scavenging capacities $\left(k_{\mathrm{s}}=k \times\right.$ [Scavenger] $)$ of the nitrate anion $\left(\mathrm{NO}_{3}{ }^{-}\right)$ for the hydrated electron $\left(\mathrm{e}_{\mathrm{aq}}^{-}\right)$, its precursor $\left(\mathrm{e}_{\mathrm{pre}}{ }^{-}\right)$, and hydrogen atom $\left(\mathrm{H}^{*}\right)$ increase proportionally, generally leading to progressively higher radiolytic yields of reduced $\mathrm{NO}_{3}{ }^{-}$ intermediates $\left(\mathrm{NO}_{3}{ }^{\cdot 2-}\right.$ and $\left.\mathrm{HNO}_{3}{ }^{-}\right)$, as given by reactions expressed in Equations 4-7.

$$
\begin{array}{ll}
\mathrm{H}_{2} \mathrm{O} w \mathrm{e}_{\mathrm{aq}}{ }^{-}, \mathrm{H}_{\mathrm{aq}}{ }^{+}, \mathrm{H}^{\cdot}, \mathrm{OH}^{\cdot}, \mathrm{H}_{2}, \mathrm{H}_{2} \mathrm{O}_{2} & \\
\mathrm{NO}_{3}{ }^{-}+\mathrm{e}_{\mathrm{pre}^{-}} \rightarrow \mathrm{NO}_{3}{ }^{-2-} & k_{5}=1 \times 10^{13} \mathrm{M}^{-1} \mathrm{~s}^{-1} \\
\mathrm{NO}_{3}{ }^{-}+\mathrm{e}_{\mathrm{aq}}{ }^{-} \rightarrow \mathrm{NO}_{3}{ }^{\cdot 2-} & k_{6}=9.7 \times 10^{9} \mathrm{M}^{-1} \mathrm{~s}^{-1} \\
\mathrm{NO}_{3}{ }^{-}+\mathrm{H}^{\cdot} \rightarrow \mathrm{HNO}_{3}{ }^{-} & k_{7}=1.0 \times 10^{7} \mathrm{M}^{-1} \mathrm{~s}^{-1}
\end{array}
$$

These reduced $\mathrm{NO}_{3}{ }^{-}$intermediates are precursors that will form $\mathrm{HNO}_{2}$, and thus their radiolytic yields in conjunction with those for $\mathrm{H}_{2} \mathrm{O}_{2}$ from water radiolysis (Equation 4) and $\mathrm{HNO}_{2}$ from direct effect formation $\left(\mathrm{HNO}_{3} w \mathrm{HNO}_{2}+\mathrm{O}\right)$ are an approximation of the reducing capability of the medium with respect to $\mathrm{Am}(\mathrm{VI})$. Table 3 gives the radiation track yields used by the multi-scale modeling approach ${ }^{29}$ for a $5.4 \mathrm{MeV} \alpha$-particle as a function of $\mathrm{HNO}_{3}$ concentration.

Table 3. Comparison of calculated radiation track yields and empirical direct effect yields for the key reducing species at $10 \mu$ s for the alpha radiolysis of aerated aqueous $\mathrm{HNO}_{3}$ solutions for a 5.4 $\mathrm{MeV} \alpha$-particle.

\begin{tabular}{lccc}
\hline Species & \multicolumn{3}{c}{ Radiolytic Yields (Species $100 \mathrm{eV}^{-1}$ ) } \\
\hline & $1.0 \mathrm{M} \mathrm{HNO}_{3}$ & $3.0 \mathrm{M} \mathrm{HNO}_{3}$ & $6.5 \mathrm{M} \mathrm{HNO}_{3}$ \\
\hline $\mathrm{H}_{2} \mathrm{O}_{2}$ & 1.37 & 1.35 & 1.23
\end{tabular}




\begin{tabular}{lccc}
$\mathrm{NO}_{3}{ }^{2-}$ & 2.61 & 1.57 & 1.6 \\
$\mathrm{HNO}_{3}{ }^{-}$ & 0.34 & 1.3 & 1.39 \\
$\mathrm{HNO}_{2, \text { direct effect }}{ }^{\dagger}$ & 0.23 & 0.64 & 1.37 \\
\hline Reducing Capability & 4.55 & 4.86 & 5.59 \\
\hline
\end{tabular}

${ }^{\dagger}$ Derived from reference 40 .

The yields of $\mathrm{Am}(\mathrm{VI})$ reducing species show a significant increase with increasing $\mathrm{HNO}_{3}$ concentration, which is to be expected from scavenging capacity and energy deposition partitioning arguments. Based on changes in track chemistry alone, it would be expected for Am(VI) to be progressively less stable with increasing $\mathrm{HNO}_{3}$ concentration due to the higher reducing capability. However, this was not observed, and indicates the trend exhibited by the empirical Am(VI) autoreduction rate coefficients are predominantly a product of bulk homogeneous chemistry.

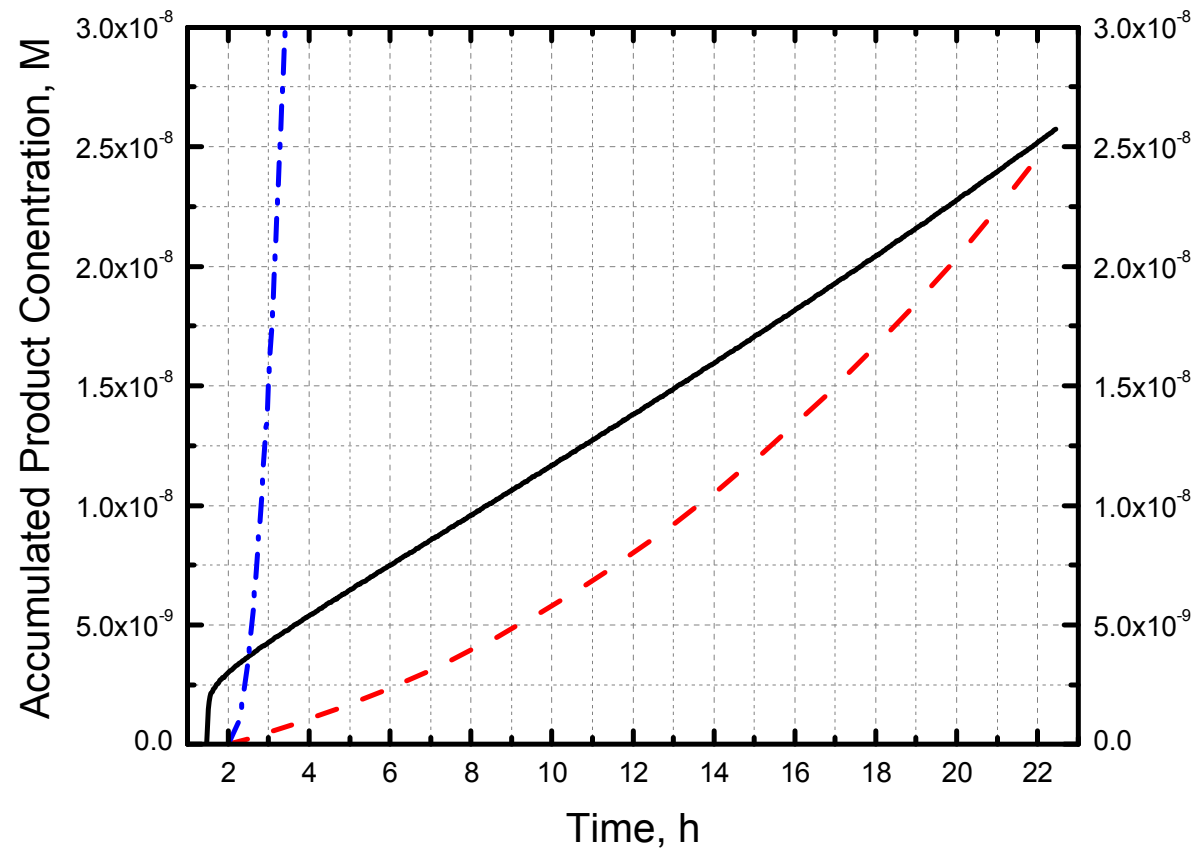

Figure 5. Accumulated product concentrations for the reaction of $\mathrm{HNO}_{2}+\mathrm{H}_{2} \mathrm{O}_{2}$ from $2.0 \mathrm{mM}$ Am- $\mathrm{HNO}_{3}$ solutions predicted by multi-scale modelling calculations: 1.0 (solid black), 3.0 (dashed red), and $6.5 \mathrm{MHNO}_{3}$ (dash-dot blue).

3.5. Bulk Homogeneous Chemistry. The concentration of radiolytically produced $\mathrm{HNO}_{2}$ increases with $\mathrm{HNO}_{3}$ concentration, which is evident from the radiolytic yields given in Table 3. 
This leads to increased competition for $\mathrm{HNO}_{2}$ between $\mathrm{Am}(\mathrm{VI})$ and $\mathrm{H}_{2} \mathrm{O}_{2}$. The accumulated product concentrations for the reaction of $\mathrm{HNO}_{2}$ and $\mathrm{H}_{2} \mathrm{O}_{2}$ as a function of nitric acid concentration are shown in Figure 6 which demonstrates this reaction is least efficient at $3.0 \mathrm{M} \mathrm{HNO}_{3}$. Consequently, in $3.0 \mathrm{M} \mathrm{HNO}_{3}$ more $\mathrm{HNO}_{2}$ is available for reaction with $\mathrm{Am}(\mathrm{VI})$ than at $1.0 \mathrm{M}$ or 6.5 $\mathrm{M} \mathrm{HNO}_{3}$. As such, this modeling demonstrates the autoreduction of hexavalent americium in nitric acid solutions is a consequence of the reactions of $\mathrm{HNO}_{2}$, and to lesser extent $\mathrm{H}_{2} \mathrm{O}_{2}$.

\section{CONCLUSIONS}

The rate of hexavalent americium autoreduction has been measured across a range of nitric acid concentrations. These rates are reported for $\mathrm{Am}(\mathrm{VI})$ autoreduction using ${ }^{243} \mathrm{Am}$ in a nitric acid solution free of any potential trace reductants. The reduction follows zero-order kinetics with respect to $[\mathrm{Am}(\mathrm{VI})]$ but first-order kinetics with respect to total americium concentration, due to reaction with the radiolysis products of americium decay. The empirical first-order rate constants are given, and compared to the limited previous work using ${ }^{241} \mathrm{Am}$. Multi-scale radiation chemical modeling including the $\alpha$-radiolysis yields for $\mathrm{HNO}_{2}$ and $\mathrm{H}_{2} \mathrm{O}_{2}$ in irradiated aqueous nitric acid agreed with the empirically modeled rate of autoreduction at various acid concentrations, strongly suggesting the proposed radiolytic mechanism.

Americium speciation in these experiments was observed by UV-vis spectroscopy, necessitating the determination of the unknown molar extinction coefficients for the $\mathrm{Am}(\mathrm{V}) 718$ $\mathrm{nm}$, and Am(VI) $996 \mathrm{~nm}$ peaks. These were obtained by iteration from initial reasonable values to obtain total americium mass balance with the known total americium concentrations. The new extinction coefficients reported here are within a general uncertainty less than $\pm 4 \%$ for $6.5 \mathrm{M}$ $\mathrm{HNO}_{3}$, and $\pm 10 \%$ for the $3.0 \mathrm{M} \mathrm{HNO}_{3}$ conditions.

Multiscale modelling demonstrated that $\mathrm{HNO}_{2}$ is the predominant reducing species under self-radiolysis conditions, as $\mathrm{H}_{2} \mathrm{O}_{2}$ possesses a lower radiolytic yield and also reacts with $\mathrm{HNO}_{2}$. Furthermore, the trends exhibited by the empirical $\mathrm{Am}(\mathrm{VI})$ autoreduction rate constants are a consequence of bulk homogenous effects affecting the available proportions of $\mathrm{HNO}_{2}$ and $\mathrm{H}_{2} \mathrm{O}_{2}$ such that $\mathrm{Am}(\mathrm{VI})$ is least stable in $3.0 \mathrm{M} \mathrm{HNO}_{3}$, relative to $1.0 \mathrm{M}$ and $6.5 \mathrm{M} \mathrm{HNO}_{3}$. Understanding the autoreduction of $\mathrm{Am}(\mathrm{VI})$ in $\mathrm{HNO}_{3}$ solutions yields significant insight into the effects of $\alpha$ radiolysis on potential americyl reprocessing flowsheets.

\section{AUTHOR INFORMATION}

Corresponding Author

*Email: travis.grimes@inl.gov

\section{ORCID}

Travis S. Grimes: 0000-0003-2751-0492 


\section{Notes}

The authors declare no competing financial interest.

\section{ACKNOWLEDGMENTS}

TSG and BJM were funded by the US DOE Office of Nuclear Energy FCR\&D Sigma Team for

Advanced Actinide Recycle under Idaho Operations Contract DEAC07-05ID14517. GPH and SPM were funded by the US-DOE Assistant Secretary for NE, under the FCR\&D Radiation Chemistry program; DOE-Idaho Operations Office Contract DE-AC07-05ID14517 and Nuclear Energy University Partnership grant DE-NE0008406. CJD was funded by DOE-NEUP under contract DE-NE0008539.

\section{REFERENCES}

1. Jha, M. K.; Kumar, V.; Singh, R. J. Review of Hydrometallurgical Recovery of Zinc from Industrial Wastes. Resour. Conserv. Recycl. 2001, 33, 1-22.

2. Habashi, G. A. Short History of Hydrometallurgy. Hydrometallurgy. 2005, 79, 15-22.

3. Rudnick, E.; Nikiel, M. Hydrometallurgical Recovery of Cadmium and Nickel from Spent Ni-Cd Batteries. Hydrometallurgy. 2007, 89, 61-71.

4. Denning, R. G.; Norris, J. O. W.; Short, I. G.; Snellgrove, T. R.; Woodwark, D. R. In Lanthanide and Actinide Chemistry and Spectroscopy. Edelstein, N. M., Ed.; ACS Symposium Series 131; American Chemical Society: Washington, DC, 1980; pp 313330.

5. Neuefeind, J.; Soderholm, L.; Skanthakumar, S. Experimental Coordination Environment of Uranyl(VI) in Aqueous Solution. J. Phys. Chem. A. 2004, 108, 2733-2739.

6. Denning, R. G. Electronic Structure and Bonding in Actinyl Ions and their Analogs. $J$. Phys. Chem. A. 2007, 111, 4125-4143.

7. Bard, A. J.; Parsons, R.; Jordan, J. Standard Potentials in Aqueous Solution; Marcel Dekker, Inc.: New York, 1985.

8. Maher, K.; Bargar, J. R.; Brown, G. E. Jr. Environmental Speciation of Actinides. Inorg. Chem. 2013, 52, 3510-3532.

9. Choppin, G. R.; Rydberg, J-O. Treatment of spent nuclear fuel. Nuclear Chemistry: Theory and Applications, $1^{\text {st }}$ edition; Pergamon Press Inc.: New York, 1980; 502-559.

10. Benedict, M.; Pigford, T. H.; Levi, H. W. Nuclear Chemical Engineering, $2^{\text {nd }}$ edition; McGraw-Hill: New York, 1981.

11. Choppin, G. R.; Liljenzin, J-O.; Rydberg J. Nuclear fuel cycle. Radiochemistry and Nuclear Chemistry, $3^{\text {rd }}$ edition; Butterworth-Heinemann: Woburn, MA, 2002; 582-641. 
12. Todd, T. A.; Wigeland, R. A. Advanced separation technologies for processing used nuclear fuel and the potential benefits to a geologic repository. In Separations for the Nuclear Fuel Cycle in the $21^{\text {st }}$ Century. Lumetta, G. L.; Nash, K. L.; Clark, S. B.; Friese, J. I., Eds.; ACS Symposium Series 933, American Chemical Society: Washington D.C., 2006; 41-55.

13. Mincher, B. J.; Martin, L. R.; Schmitt, N. C. Tributylphosphate Extraction Behavior of Bismuthate-Oxidized Americium. Inorg. Chem. 2008, 47, 6984-6989.

14. Mincher, B. J.; Martin, L. R.; Schmitt, N. C. Diamylamylphosphonate Solvent Extraction of Am(VI) from Nuclear Fuel Raffinate Simulant Solution. Solvent Extr. Ion Exch. 2012, 30, 445-456.

15. McCann, K.; Mincher, B. J.; Schmitt, N.C.; Braley, J.C. Hexavalent actinide extraction using N,N-dialkyl Amides. J. Ind. Eng. Chem. manuscript in review.

16. Asprey, L. B.; Stephanou, S. E.; Penneman, R. A. A New Valence State of Americium, Am(VI). J. Am. Chem. Soc. 1950, 72 (3), 1425-1426.

17. Asprey, L. B.; Stephanou, S. E.; Penneman, R. A. Hexavalent Americium. J. Am. Chem. Soc. 1951, 73 (12), 5715-5717.

18. Werner, L. B.; Perlman, I. The Pentavalent State of Americium. J. Am. Chem. Soc. 1951, 73 (1), 495-496.

19. Gunn, S. R.; Cunningham, B. B. The Heats of Formation of $\mathrm{AmO}_{2}{ }^{+}(\mathrm{aq})$ and $\mathrm{AmO}_{2}{ }^{2+}$ (aq) in $1 \mathrm{M} \mathrm{HClO}_{4}$. J. Am. Chem. Soc. 1957, 79 (7), 1563-1565.

20. Penneman, R. A.; Asprey, L. B. A Review of Americium and Curium Chemistry. $1^{\text {st }}$ International Conference on Peaceful Uses of Atomic Energy, Geneva, 1956, 7, 355-362.

21. Coleman, J. S. The Kinetics of the Disproportionation of Americium(V). Inorg. Chem. 1963, 2 (1), 53-57.

22. Hall, G. R.; Herniman, P. D. The Separation and Purification of Americium-241 and the Absorption Spectra of Tervalent and Quinquevalent Americium Solutions. J. Chem. Soc. 1954, 2214-2221.

23. Hall, G. R.; Markin, T. L. The Self-Reduction of Americium(V) and (VI) and the Disproportionation of Americium(V) in Aqueous Solution. J. Inorg. Nucl. Chem. 1957, 4 , 296-303.

24. Keenan, T. K. Americium and Curium. J. Chem. Ed. 1959, 36 (1), 27-31.

25. Mincher, B. J.; Precek, M.; Mezyk, S. P.; Elias, G.; Martin, L. R.; Paulenova, A. The Redox Chemistry of Neptunium in $\gamma$-irradiated Aqueous Nitric Acid. Radiochim. Acta. 2013, 101, 259-265.

26. Horne, G.P.; Grimes, T.S.; Mincher, B.J.; Mezyk, S.P. Re-evaluation of Neptunium-nitric Acid Radiation Chemistry by Multi-Sacale Modeling. J. Phys. Chem. B. 2016, 120 (49), 12643-12649.

27. Pimblott, S. M.; LaVerne, J. A.; Mozumder, A. Monte Carlo Simulation of Range and Energy Deposition by Electrons in Gaseous and Liquid Water. J. Phys. Chem., 1996, 100, 8595-8606.

28. Pimblott, S. M.; LaVerne, J. A. Effects of Track Structure on the Ion Radiolysis of the Fricke Dosimeter. J. Phys. Chem. A, 2002, 106, 9420-9427. 
29. Clifford, P.; Green, N. J. B.; Oldfield, M. J.; Pilling, M. J. ; Pimblott, S. M. Stochastic Models of Multi-Species Kinetics in Radiation-Induced Spurs. J. Chem. Soc., Faraday Trans., 1986, 82, 2673-2689.

30. Horne, G. P.; Donoclift, T. A.; Sims, H. E.; Orr, R. M.; Pimblott, S. M. Multi-Scale Modelling of the Gamma Radiolysis of Nitrate Solutions. J. Phys. Chem. B, 2016, 120, 11781-11789.

31. Garaix, G.; Horne, G. P.; Venault, L.; Moisy, P.; Pimblott, S. M.; Marignier, J. -L.; Mostafavi, M. Decay Mechanism of $\mathrm{NO}_{3}{ }^{\cdot}$ Radical in Highly Concentrated Nitrate and Nitric Acidic Solutions in the Absence and Presence of Hydrazine. J. Phys. Chem. B, 2016, 120, 5008-5014.

32. Zalupski, P. R.; Grimes, T. S.; Heathman, C. R. Spectroscopy Manuscript in Preparation.

33. Runde, W. H.; Mincher, B. J. Higher Oxidation States of Americium: Preparation, Characterization and Use for Separations. Chem. Rev. 2011, 111, 5723-5741.

34. Schulz, W. W. The Chemistry of Americium. DOE Technical Information Center: Oak Ridge, TN, 1976.

35. Sinkov, S. I.; Lumetta, G. J. Americium(III) Oxidation by Copper(III) Periodate in Nitric Acid Solution as Compared with the Action of $\mathrm{Bi}(\mathrm{V})$ compounds of Sodium, Lithium, and Potassium. Radiochim. Acta. 2015, 103 (8), 541-552.

36. Zaitsev, A. A.; Kosyakov, V. N.; Rykov, A. G.; Sobolov, Y. P.; Yakovlev, G. N. Tadiolytic Reduction of Am(VI) and Am(V), Sov. At. Energy (Engl. Transl.), 1960, 562569.

37. Dares, C. J.; Lapides, A. M.; Mincher, B. J.; Meyer, T. J. Electrochemical Oxidation of ${ }^{243} \mathrm{Am}(\mathrm{III})$ in Nitric Acid by a Terpyridyl-derivatized Electrode. Science. 2015, 350 (6261), 652-655.

38. LaVerne, J.A. Radiation chemical effects of heavy ions: In Mozumder, A.; Hatano, Y. Charged Particle and Photon Interactions with Matter. 2004, Marcel Dekker, NY, USA, pp. 403-429.

39. Davis, W.; De Bruin, H. J. New Activity Coefficients of 0 - 100 Per Cent Aqueous Nitric Acid. J. Inorg. Nucl. Chem., 1964, 26, 1069-1083.

40. Jiang, P.Y.; Nagaishi, R.; Yotsuyanagi, T.; Katsumura, Y.; Ishigure, K. Gamma Radiolysis Study of Concentrated Nitric Acid Solutions. J. Chem. Soc. Faraday Trans., 1994, 90, 93-95. 
For Table of Content Graphics Only

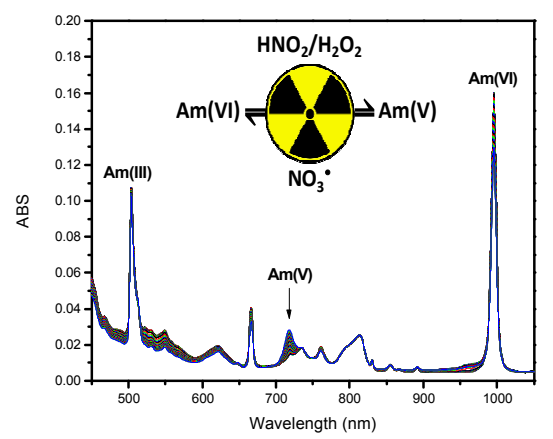

SYNOPSIS: Trivalent americium is oxidized to the hexavalent state using sodium bismuthate and copperIII periodate. Higher valent state americium is reduced to the pentavalent state and eventually back to the trivalent state through an autoreduction process induced by alpha particle radiolysis of the nitric acid system. Empirical rate constants were determined for the autoreduction processes and multi-scale modeling was used to validate the empirical results providing a deeper understanding radiation chemistry in the nitric acid systems. 